Int. J. Electrochem. Sci., 12 (2017) 4025 - 4034

\title{
Application of Ionic Liquid-Graphene-NiO Hollowsphere Composite Modified Electrode for Electrochemical Investigation on Hemoglobin and Electrocatalysis to Trichloroacetic Acid
}

\author{
Wenshu Zhao, Xiaoyan Li, Zuorui Wen, Xueliang Niu, Qingfeng Shen, Zhaolan Sun, Ruixia Dong, \\ Wei Sun ${ }^{*}$ \\ Key Laboratory of Tropical Medicinal Plant Chemistry of Ministry of Education, College of \\ Chemistry and Chemical Engineering, Hainan Normal University, Haikou 571158, P R China, \\ *E-mail: swyy26@ hotmail.com
}

doi: $10.20964 / 2017.05 .06$

Received: 2 January 2017 / Accepted: 8 March 2017 / Published: 12 April 2017

In this present paper $\mathrm{NiO}$ hollowsphere was synthesized by a solvothermal method. Then it characterized by different methods including powder X-ray diffraction and scanning electron microscopy. $\mathrm{NiO}$ hollowsphere was further mixed with hemoglobin $(\mathrm{Hb})$, ionic liquid and graphene (GR) to get a biocomposite, which was casted on carbon ionic liquid electrode. Spectroscopic data showed that $\mathrm{Hb}$ kept its native structure in the mixture. Direct electron transfer of $\mathrm{Hb}$ were investigated with a pair of well-defined quasi-reversible redox peaks appeared and the formal peak potential $\left(E^{0^{\prime}}\right)$ was got at $-0.341 \mathrm{~V}$ (vs. SCE). The $\mathrm{Hb}$ modified electrode showed excellent electrocatalysis to trichloroacetic acid (TCA) reduction. Under the selected conditions the currents had a good linear relationship with TCA concentration from 1.5 to $10.0 \mathrm{mmol} \mathrm{L}^{-1}$ and the detection limit was $0.5 \mathrm{mmol}$ $\mathrm{L}^{-1}(3 \sigma)$. This $\mathrm{Hb}$ based electrode exhibited good stability and reproducibility, which could be used for third-generation electrochemical biosensor.

Keywords: NiO hollowsphere, Direct electrochemistry, Hemoglobin, Carbon ionic liquid electrode, Trichloroacetic acid.

\section{$\underline{\text { FULL TEXT }}$}

(C) 2017 The Authors. Published by ESG (www.electrochemsci.org). This article is an open access article distributed under the terms and conditions of the Creative Commons Attribution license (http://creativecommons.org/licenses/by/4.0/). 